\title{
One Decade's Research Efforts in Hungary to Develop a Bisexual Lure for the Cotton Bollworm Helicoverpa armigera Hübner
}

\author{
M. TÓTH ${ }^{1 *}$, A. NAGY ${ }^{2}$, I. SZARUKÁN ${ }^{2}$, K. ARY ${ }^{2}$, A. CSERENYEC ${ }^{2}$, B. FENYŐDI ${ }^{2}$, \\ D. GOMBÁS ${ }^{2}$, T. LAJKÓ ${ }^{2}$, L. MERVA ${ }^{2}$ J. SZABÓ ${ }^{2}$, P. WINKLER ${ }^{2}$ and J. K. JÓSVAI ${ }^{1}$ \\ ${ }^{1}$ Plant Protection Institute, CAR, Budapest, P. O. Box. 102, H-1525, Hungary \\ ${ }^{2}$ Faculty of the Agricultural and Food Sciences and Environmental Management, Institute of Plant Protection, \\ University of Debrecen, Debrecen, P. O. Box 400, H-4002, Hungary
}

(Received: 8 January 2020; accepted: 22 January 2020)

\begin{abstract}
The addition of synthetic $(E)$-anethol to the known attractant phenylacetaldehyde synergized attraction of the cotton bollworm Helicoverpa armigera, the blend invariably catching 4 to 6 times more than phenylacetaldehyde on its own. Highest catches were recorded by the 1:1-3:1 blends. The addition of salicyl aldehyde, \pm linalool, $(R)$-(+)-limonene, 2-methoxybenzyl alcohol and 4-methoxybenzyl alcohol (compounds described earlier in the literature as co-attractants for H. armigera), increased catches when added to phenylacetaldehyde. However, the addition of these compounds did not increase catches of the $(E)$-anethol + phenylacetaldehyde blend. When directly compared with performance of the synthetic pheromone, the $(E)$-anethol + phenylacetaldehyde blend caught an average of $27 \%$ of the catch in pheromone baited traps. On an average $79 \%$ of moths caught in traps with the $(E)$-anethol + phenylacetaldehyde blend were females, while traps with pheromone caught only males. The $(E)$-anethol + phenylacetaldehyde blend described in this study may form the basis for the development of an efficient bisexual lure for $H$. armigera AFTER further optimization.
\end{abstract}

Keywords: Bisexual attractant, phenylacetaldehyde, anethol, trapping, monitoring.

The cotton bollworm (Helicoverpa armigera Hübner, Lepidoptera: Noctuidae) is an important polyphagous pest of vegetables and field crops in the Old World (Europe, Asia and Africa) where it is generally controlled by insecticide sprays, but it also appeared in Australia and even in South America (Kriticos et al., 2015). Early detection and monitoring of occurrence of the adult moths for optimal timing of pesticide treatments is necessary.

Pheromone traps are widely used in numerous pest Lepidoptera for detection and monitoring purposes. Female-produced pheromone of $H$. armigera contained (Z)-11hexadecenal and (Z)-9-hexadecenal (Dunkelblum et al., 1980; Nesbitt et al., 1980).

However, the disadvantage of pheromone-baited traps is that they will capture only males. Traps capable of capturing females could provide data which could be used in a number of other ways. For example, based on female catches giving information on the

*Corresponding author; e-mail: toth.miklos@agrar.mta.hu

This paper is dedicated to the memory of Peter J. Landolt - his scientific achievements keep him among us. 
female flight pattern, more accurate estimates can be given on the timing of oviposition, and thus result in more precise pest control decisions (Wall 1989; Witzgall et al. 2010). Beyond that efficient and sufficiently selective lures catching both males and females (bisexual lures) can also be used in mass-trapping, and lure-and-kill techniques.

Phenylacetaldehyde (PHENAL) has been described as generally attractive to Lepidoptera (Cantelo and Jacobson, 1979; Creighton et al., 1973; Meagher, 2001), particularly to noctuid and pyralid species. Catches of both sexes of $H$. armigera in traps baited with PHENAL lures have been reported previously (Pawar et al., 1983; Tóth et al., 2010). However, general experience showed that captures in traps baited with PHENAL only are too low to allow for practical applications (Tóth et al., unpublished).

This present research was undertaken in the search for possible synergists which, when added to PHENAL, would yield catches high enough to draw plant protection decisions reliably. Starting point was provided by a chance finding, when we recorded in an experiment originally aimed at capturing other noctuids, that a four-component mixture of PHENAL $+(E)$-anethol $($ ANET $)+$ cinnamyl alcohol $(\mathrm{cinnOH})+$ cinnamic acetate (cinnAC) caught a mean/trap of 25.2 vs. a mean/trap of $11.4 \mathrm{H}$. armigera in traps with PHENAL only ( $<<0.0283$ by Mann-Whitney U test, total caught in test 183 moths) (M. Tóth and I. Szarukán, unpublished). This suggested that the three components added, or some of them may have had some positive influence on captures of H. armigera with PHENAL.

\section{Materials and Methods}

\section{Field tests}

Tests aimed at catching $H$. armigera were conducted at several sites in Hungary using generally accepted methods in trapping experiments of the same nature (Roelofs and Cardé, 1977).

Traps were arranged as blocks so that each block contained one trap of each treatment. Traps within blocks were separated by $8-10 \mathrm{~m}$, and blocks were sited at least $30 \mathrm{~m}$ apart. Unless otherwise stated at each test site 5 blocks of traps were operated. Traps were inspected at some days' intervals (preferably twice weekly), when captured insects were recorded and removed.

In the tests, funnel traps CSALOMON® VARL were used. These traps have previously been used for trapping several moth species of larger size (Tóth et al., 2000, 2010; Subchev et al., 2004). Photos of the trap can be viewed at www.csalomontraps.com. For killing captured insects, a small piece $(1 \times 1 \mathrm{~cm})$ of a household anti-moth insecticide strip (Chemotox ${ }^{\circledR}$ SaraLee, Temana Intl. Ltd, Slouth, UK; active ingredient $15 \%$ dichlorvos) was placed into the catch container of traps.

\section{Baits}

Synthetic compounds applied in baits were obtained from Sigma-Aldrich Kft. (Budapest, Hungary). All compounds were $>95 \%$ pure as stated by the supplier. The same dispenser types as described earlier (Tóth et al., 2019) were used: polyethylene (PE) bag, 
PE vial, emitting the compounds through their walls, and polypropylene (PP) syringe (with an opening of $4 \mathrm{~mm}$ diameter, for letting the compounds directly evaporate into the environment) dispensers.

Unless otherwise stated the dose of single compounds was $100 \mathrm{mg} / \mathrm{dispenser}$ in case of PE bag and PE vial dispensers, while $400 \mathrm{mg}$ in PP syringe dispensers. In case of testing mixtures, compounds were loaded into the same dispenser.

Pheromone lures used were the commercial $H$. armigera lures available from CSALOMON® (PPI CAR, Budapest, formulated on rubber dispenser).

\section{Statistical analysis}

As it is frequently found in field trapping experiments, the catch data (even after transformation) usually did not fulfil requirements for a parametric analysis. Therefore, unless otherwise stated, data were analysed by the non-parametric Kruskal-Wallis test. When the Kruskal-Wallis test showed significance, differences between treatments were analysed by pairwise comparisons with Mann-Whitney U test.

All statistical procedures were conducted using the software packages StatView ${ }^{\circledR}$ v4.01 and SuperANOVA® v1.11 (Abacus Concepts, Inc., Berkeley, CA, USA).

\section{Experimental details}

Experiment 1. The objective of this test was to confirm the positive influence of the addition of ANET + cinnOH + cinnAC to PHENAL (preliminary chance finding mentioned in the Introduction), and to crosscheck the relative importance of the compounds added. Treatments included (formulated in PE bag dispensers): PHENAL, PHENAL plus ANET, cinnOH and cinnAC in ternary and binary combinations and unbaited controls.

The test was run parallel at two sites: Forráskút, Csongrád county, May 10-October 9, 2008 and Nyírmeggyes, Szabolcs-Szatmár-Bereg county, May 25-October 4, 2008.

Experiment 2. The objective of this test was to recheck whether the addition of cinnAC to the PHENAL + ANET blend (which combination caught numerically the most moths in Exp. 1) has any positive influence. Treatments included (formulated in PE bag dispensers): PHENAL, PHENAL plus ANET, and PHENAL + ANET + cinnAC.

The test was conducted at: Forráskút, Csongrád county, May 30-October 4, 2009.

Experiment 3. In this test we aimed at further confirming the positive influence of the addition of ANET to PHENAL. Treatments included (formulated in PE bag dispensers): PHENAL and PHENAL + ANET.

The test was run parallel at three sites: Forráskút, Csongrád county, May 30-October 3, 2010, Mezőberény, Békés county, June 1-September 30, 2010 and Dömsöd, Pest county, July 25-November 11, 2011.

Experiment 4. The objective of the test was to study the influence of adding ANET in increasing ratios to PHENAL. Treatments included (formulated in PE bag dispensers): PHENAL on its own, binary mixtures of PHENAL with ANET in 10:1, 10:3, 1:1, and 3:10 ratios, and unbaited controls. 
The test was run parallel at two sites: Nagyszénás, Békés county June 8-November 4, 2018 and Konyár, Hajdú-Bihar county June 12-November 2, 2018.

Experiment 5. In this test the performance of the PHENAL + ANET blend formulated in three different types of dispensers was compared. Treatments included PE vial, $\mathrm{PE}$ bag and PP syringe dispensers and unbaited controls. Although no exact measurements of release rates were performed, we supposed that $\mathrm{PE}$ vial dispensers were emitting at a lower rate than PE bag dispensers (because their wall was much thicker), and PP syringe dispensers were emitting faster than PE bag dispensers, since evaporating compounds could access directly the air outside through the open hole.

The test was run parallel at three sites: Vésztő, Békés county, June 1-October 22, 2012, Szeged, Békés county, June 1 October 23, 2012 and Debrecen, Hajdú-Bihar county, July 17-October 22, 2013.

Experiment 6. In this test the effect of the addition of other synergistic compounds found in the literature to PHENAL or the PHENAL + ANET mixture was studied. Treatments included PHENAL only, PHENAL + ANET, and the combinations of these two treatments with mixtures of salicyl aldehyde (SALALD) $+(R)-(+)$ limonene (LIMON) + (+ /-)-linalool (LINAL) (Cork, 2016) or 2-methoxybenzyl alcohol $(2 \mathrm{METOH})+4-$ methoxybenzyl alcohol (4METOH) (Sexton, 2002) and unbaited traps.

The test was run parallel at two sites: Karcag, Jász-Nagykun-Szolnok county, June 4-October 29, 2017, and Tiszadada, Szabolcs-Szatmár-Bereg county, June 10-November 2, 2017.

Experiment 7. In this test the performance of the binary PHENAL + ANET lure (formulated in PE bag dispensers) was compared with that of synthetic H. armigera pheromone (commercial lure from the CSALOMON® trap family, Plant Protection Institute, CAR, Budapest, Hungary). The test was run in two consecutive years in a mixed orchard at Érd-Elviramajor (Pest county), August 14-October 22, 2015 and June 1-October 14, 2016. In each year four blocks of traps were operated.

\section{Results}

Several moth spp. belonging to Noctuidae, Pyralidae and occasionally to other moth families were caught in the experiments conducted at different localities. In the present study we restrict our report only on catches of $H$. armigera. Catches of other moths will be reported elsewhere in the future.

In Exp. 1. all baited treatments caught significantly more of $H$. armigera than unbaited traps (Fig. 1A,B). By tendency highest mean catches were recorded in the traps baited with combinations containing ANET (both ternary and quaternary mixtures, all blends being significantly different from PHENAL in Exp. 1A (Fig. 1A), while in Exp. 1B only the quaternary blend caught significantly more than PHENAL (Fig. 1B). The ternary blend missing ANET was similar to PHENAL in both tests. 
In Exp. 2. both the binary blend with ANET and the ternary blend containing also cinnAC caught significantly more than PHENAL only (Fig 1.C), and they were not different from each other. In this test no unbaited traps were operated.

In Exp. 3, which was aimed at confirming the positive effect of the addition of ANET, at all three sites the PHENAL + ANET blend caught five to six fold more than PHENAL only (Fig. 2A,B,C).

When testing a dose range of ANET added to PHENAL in Exp. 4, at both sites a clear dose/response relationship was observed, with increasing catches as the dose was increased (Fig. 3A,B). The addition of as little as 30\% or 10\% (in Exp. 3A and 3B, resp.)

A

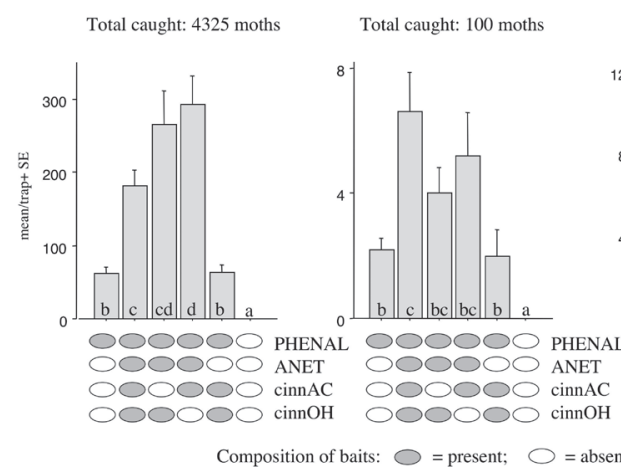

$\mathrm{C}$

Total caught: 1181 moths

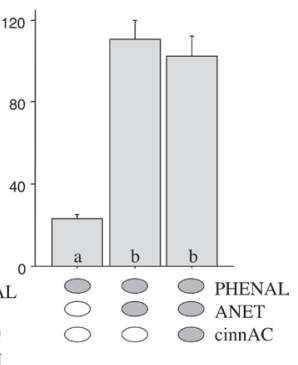

Fig. 1. Mean catches of Helicoverpa armigera in traps baited with phenylacetaldehyde (PHENAL), its binary blend with $(E)$-anethol (ANET), and its ternary and quaternary blends with $(E)$-cinnamic acetate (cinnAC) and $(E)$-cinnamyl alcohol $(\mathrm{cinnOH})$ and in unbaited traps.

$\mathrm{A}=$ Exp. 1 Forráskút, $\mathrm{B}=$ Exp. 1 Nyírmeggyes, $\mathrm{C}=$ Exp. 2 Forráskút

Columns with same letter within a diagram do not differ significantly at $\mathrm{p}=5 \%$ by Kruskall-Wallis test, followed by pairwise comparisons with Mann-Whitney U test.

A

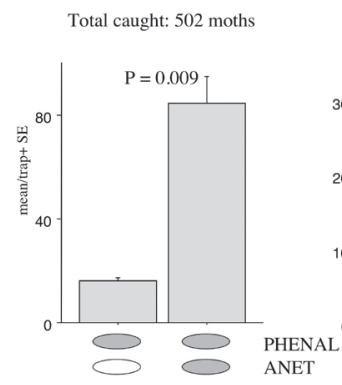

$\mathrm{B}$

Total caught: 162 moths

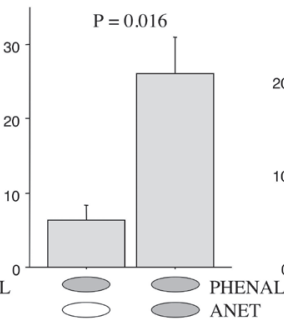

Total caught: 125 moths

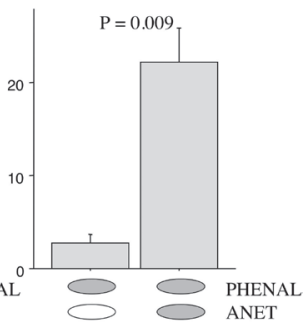

Composition of baits: $\square=$ present $;=$ absent

Fig. 2. Mean catches of Helicoverpa armigera in traps baited with phenylacetaldehyde (PHENAL), and its binary blend with $(E)$-anethol (ANET) in Exp. 3.

$\mathrm{A}=$ Forráskút, $\mathrm{B}=$ Mezöberény, $\mathrm{C}=$ Dömsöd. $\mathrm{P}$ values derive from Mann-Whitney $\mathrm{U}$ test) 
A

Total caught: 355 moths

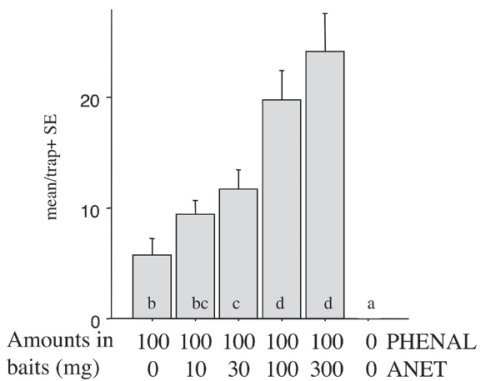

B

Total caught: 1046 moths

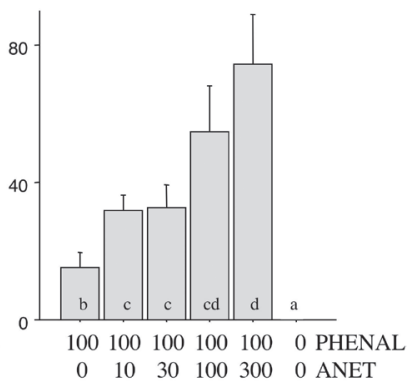

Fig. 3. Mean catches of Helicoverpa armigera in traps baited with phenylacetaldehyde (PHENAL), and its blend in different ratios with $(E)$-anethol (ANET), or unbaited traps in Exp. 4. $\mathrm{A}=$ Nagyszénás, $\mathrm{B}=$ Konyár

Columns with same letter within a diagram do not differ significantly at $\mathrm{p}=5 \%$ by Kruskall-Wallis test, followed by pairwise comparisons with Mann-Whitney U test.

A

Total caught: 75 moths

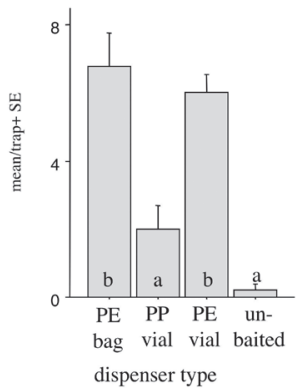

B

Total caught: 87 moths

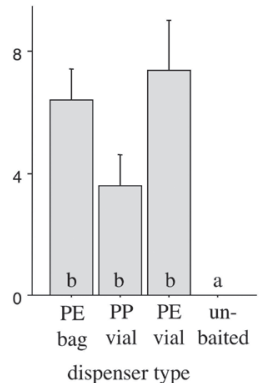

$\mathrm{C}$

Total caught: 167 moths

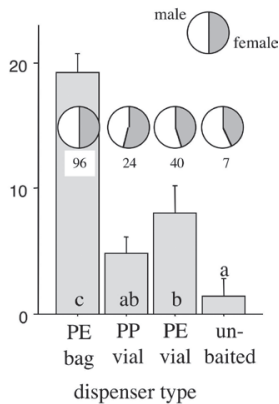

Fig. 4. Mean catches of Helicoverpa armigera in traps baited with the binary phenylacetaldehyde

$(\mathrm{PHENAL})+(E)$-anethol $(\mathrm{ANET})$ mixture in different dispensers, or unbaited traps in Exp. 5 . $\mathrm{A}=$ Vésztő, $\mathrm{B}=$ Szeged, $\mathrm{C}=$ Debrecen

Columns with same letter within a diagram do not differ significantly at $\mathrm{p}=5 \%$ by Kruskall-Wallis test, followed by pairwise comparisons with Mann-Whitney U test.

Catches were sexed in C (Exp. 5 at Debrecen) only. The numbers below circles showing male/female ratios give total numbers caught and sexed in the respective treatment.

of ANET was already enough to yield significantly higher catches than PHENAL alone. Maximal catches were recorded in the 1:1 and 1:3 PHENAL:ANET mixtures.

In Exp. 5. all baited treatments caught more $H$. armigera than unbaited controls (Fig. 4A,B,C), with the exception of PP vials in Exp. 4A and C. In general, the most efficient $\mathrm{PE}$ bag and $\mathrm{PE}$ vial dispensers were catching similarly, with the exception in Exp. 4C, where PE bag caught significantly more. Female ratio in catches was calculated only in Exp. 4C, where all treatments caught a similar ratio from female moths, ranging from $43 \%$ to $54 \%$. 
A

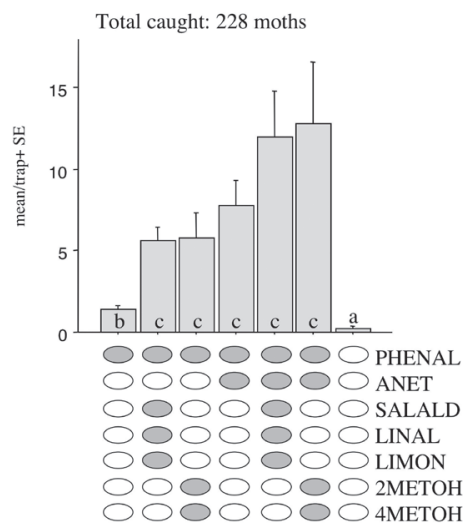

B

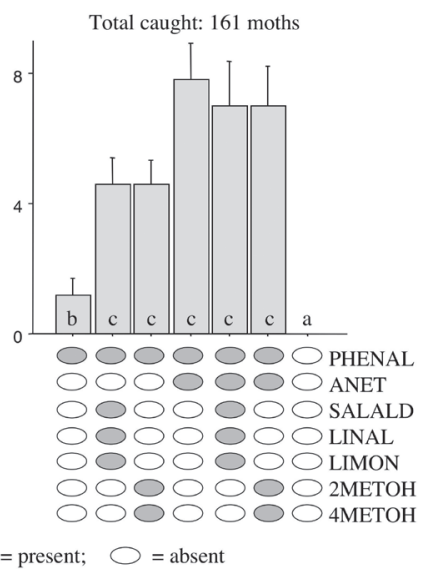

Fig. 5. Mean catches of Helicoverpa armigera in traps baited with phenylacetaldehyde (PHENAL), and its blend with $(E)$-anethol (ANET), when the ternary mixture of salicyl aldehyde (SALALD) linalool

(LINAL) limonene (LIMON) or the binary mixture of 2-methoxybenzyl alcohol (2METOH) and 4-methoxybenzyl alcohol (4METOH) were added to the first two treatments, and in unbaited traps in Exp. 6. $\mathrm{A}=$ Karcag, $\mathrm{B}=$ Tiszadada

Columns with same letter within a diagram do not differ significantly at $\mathrm{p}=5 \%$ by Kruskall-Wallis test, followed by pairwise comparisons with Mann-Whitney U test.

In Exp. 6. already PHENAL only caught more than unbaited controls, and all other treatments caught significantly more than PHENAL alone (Fig. 5). We recorded no significant differences among these treatments.

When comparing the performance of the blend of PHENAL + ANET with that of synthetic $H$. armigera pheromone in Exp. 7, traps with the PHENAL + ANET blend caught significantly less (8.5\% and $45.5 \%$ of mean catch, in 2015 and 2016, resp.) than moths caught in traps with synthetic pheromone, however, the majority of the moths in traps with the PHENAL + ANET lure were females (Table 1). Only males were caught in traps with the pheromone.

\section{Table 1}

Mean/trap/inspection ( \pm SE) catches of Helicoverpa armigera in traps baited with the synthetic pheromone or with the bisexual lure in Exp. 7. in two consecutive years

\begin{tabular}{lll}
\hline Treatment & \multicolumn{2}{l}{ Mean/trap $( \pm$ SE $)$} \\
\cline { 2 - 3 } & 2015 & 2016 \\
\hline Pheromone lure & $58.7 \pm 13.8$ & $5.5 \pm 1.1$ \\
Bisexual lure & $5.0 \pm 1.0$ & $2.5 \pm 0.4$ \\
P value (Student t test) & $<0.001$ & 0.007 \\
$\%$ of females (in bisexual lure) & $81.8 \%^{*}$ & $76.6 \%$ \\
total caught in test & 1708 & 926 \\
\hline
\end{tabular}

\footnotetext{
* based on 297 individuals, randomly selected from catch.
} 


\section{Discussion}

In the present study we confirmed field activity of PHENAL on $H$. armigera, as reported in earlier literature (Pawar et al., 1983; Tóth et al., 2010). Further, we showed out that the addition of ANET to PHENAL resulted in increased catches of $H$. armigera: traps with the binary lure invariably catching 4-6 times more than catches with PHENAL only. ANET, when added to PHENAL showed a clear dose/response, blends with higher ratios catching more $H$. armigera. Among different dispenser types loaded with the binary ANET plus PHENAL blend, catches tended to be lower with the dispenser releasing at the highest rate, suggesting that the optimal release window has been surpassed.

However, it appears that the level of catches in traps with the ANET plus PHENAL blend is still highly variable and uncertain for practical applications (performance of 9 and $45 \%$ of moths caught in the binary blend vs. synthetic pheromone, which latter is the most powerful and sensitive detection tool for this pest species at present), consequently further optimization should be done.

ANET as a co-attractant for $H$. armigera has been mentioned as part of a multicomponent blend (consisting of PHENAL, ANET, 2METOH 4METOH and including $\beta$-caryophyllene, 4-methoxy-2-phenethanol, and (Z)-3-hexenyl salicylate) (Sexton, 2002), however, no data has been presented on binary lures of ANET plus PHENAL.

In this study we confirmed that the addition of some already described compounds to PHENAL increased catches (for SALALD, LIMON and LINAL, based on Cork, 2016; for 2METOH and 4METOH, based on Sexton, 2002). Interestingly, the above compounds did not increase catches further when presented together with the binary PHENAL + ANET blend. However, in the present study the amounts of components in the blends were kept at the same dose. Optimizing blends with varying ratios of compounds may open up new avenues in the search for a more potent $H$. armigera lure.

Also, other compounds described as meaningful in the chemical communication of $H$. armigera should be tested with the hope of achieving an improved lure. Also, the electrophysiologically active benzaldehyde, (Z)-6-nonenol and salicylaldehyde (originally identified from poplar leaves) combined with PHENAL enhanced male response rates in the wind tunnel (Deng et al., 2004). Also, better wind tunnel responses have been reported when $a$-pinene, limonene, cineole, and (Z)-3-hexenyl salicylate were added to PHENAL (Gregg et al., 2010). When analysing the emissions of the African marigold (Tagetes erecta L.) benzaldehyde, $(S)$-(-)-limonene, $(R, S)$-( +/-)-linalool, $(E)$-myroxide, $(Z)$ beta-ocimene, phenylacetaldehyde, and $(R)-(-)$-piperitone were identified, and this blend evoked similar responses from $H$. armigera in wind tunnel as natural flowers did (Bruce and Cork, 2001). Also, $\beta$-caryophyllene, 4-methoxy-2-phenethanol, and ( $Z$ )-3-hexenyl salicylate evoked electophysiological responses and influenced oviposition behavior (Burguiere et al., 2001, Gregg et al., 2010, Srinivasan et al., 2006).

On the other hand, the optimization of the ratio of ANET and PHENAL could yield a better attractant lure. From the dose/response shown in Fig 3 it appeared that catches increased with increasing amounts of ANET but the optimal ratio has not been reached.

As opposed to traps with the pheromone (which caught only males), many females were caught in traps with the ANET plus PHENAL blend in this study. Sex ratios in binary baited traps were supposedly mirroring the natural sex ratio of the local populations. Future studies on whether the female percentages in the catch represent the actual sex 
ratio or are biased for some reason should be conducted for better management of $H$. armigera.

The fact that the new lure is catching also females is of great importance, as protandry is a phenomenon occurring frequently in insects (Muralimohan and Srinivasa, 2008). Protandry could be observed well with traps baited with a lure capable to attract both male and female specimens. The difference of the flight of females vs. males may have great significance in pest management. Timing of the insecticide sprays to the flight of females could be more precise as it evidently correlates better to the egg laying than catch patterns of males recorded in pheromone traps (Knight and Light, 2004, 2005).

\section{Acknowledgements}

The authors are greatly indebted to all the farmers who allowed experiments to be conducted on their respective fields.

\section{Literature}

Bruce, T. J. and Cork, A. (2001): Electrophysiological and behavioral responses of female Helicoverpa armigera to compounds identified in flowers of African marigold, Tagetes erecta. J. Chem. Ecol. 27, 1119-1131.

Burguiere, L., Marion-Poll, F. and Cork, A. (2001): Electrophysiological responses of female Helicoverpa armigera (Hübner) (Lepidoptera; Noctuidae) to synthetic host odours. J. Insect Physiol. 47, 509-514.

Cantelo, W. W. and Jacobson, M. (1979): Phenylacetaldehyde attracts moths to bladder flower and to blacklight traps. Environ. Entomol. 8, 444-447.

Cork, A. (2016): Insect attractant compositions. United States Patent US 9, 3867,766 B2.

Creighton, C. S., McFadden, T. L. and Cuthbert, E. R. (1973): Supplementary data on phenylacetaldehyde: an attractant for Lepidoptera. J. Econ. Entomol. 66, 114-116.

Deng Jian-yu, Huang Yong-ping, Wei Hong-yi and Du Jia-wei (2004): EAG and behavioral responses of Helicoverpa armigera males to volatiles from poplar leaves and their combinations with sex pheromone. J. Zhejiang Univ. Sci. 5, 1577-1582.

Dunkelblum, E. Gothilf, S. and Kehat, M. (1980): Identification of the sex pheromone of the cotton bollworm, Heliothis armigera, in Israel. Phytoparasitica. 8, 209-211.

Gregg, P. C., Del Socorro A. P. and Henderson, G. S. (2010): Development of a synthetic plant volatile-based attracticide for female noctuid moths. II. Bioassays of synthetic plant volatiles as attractants for the adults of the cotton bollworm, Helicoverpa armigera (Hubner) (Lepidoptera: Noctuidae). Aust. J. Ent. 49, 21-30.

Knight, A. L. and Light, D. M. (2004): Use of ethyl and propyl (E,Z)-2,4-decadienoate in codling moth management: Improving monitoring in Bartlett pear with high dose lures. J. Ent. Soc. British Columbia 101, 45-52.

Knight, A. L. and Light, D. M. (2005): Timing of egg hatch by early-season codling moth (Lepidoptera: Tortricidae) predicted by moth catch in pear ester- and codlemone-baited traps. Can. Ent. 137, 728-738.

Kriticos, D., Ota, N., Hutchison, W., Beddow, J., Walsh, T., Tay, W., Borchert, D., Paula-Moraes, S., Czepak, C. and Zalucki, M. (2015): The potential distribution of invading Helicoverpa armigera in North America: is it just a matter of time? PloS One 10(3):e0119618, doi:10.1371/journal.pone.0119618

Meagher, R. L. (2001): Collection of soybean looper and other noctuids in phenylacetaldehyde-baited traps. Fla. Entomol. 84, 154-155.

Muralimohan, K. and Srinivasa, Y. B. (2008): Occurrence of protandry in an aseasonal multivoltine moths: Implications for body-size evolution. Current Science 94, 513-518.

Nesbitt, B. F., Beevor, P. S., Hall, D. R. and Lester, R. (1980): (Z)-9-Hexadecenal: a minor component of the femle sex pheromone of Heliothis armigera (Hübner) (Lepidoptera, Noctuide). Ent. Exp. Appl. 27, 306-308.

Pawar, C. S., Srivastava, C. P., and Reed, W. (1983): Phenylacetaldehyde: an attractant for Heliothis armigera. Int. Chickpea Newsletter 1983, 27-28. 
Roelofs, W. L. and Cardé, R. T. (1977): Responses of Lepidoptera to synthetic sex pheromone chemicals and their analogues. Annu. Rev. Entomol. 22, 377-405.

Sexton, S. (2002): Noctuid attractant composition. United States Patent US 20050147640 A1

Srinivasan, R., Uthamasamy, S. and Talekar, N. S. (2006): Characterization of oviposition attractants of Helicoverpa armigera in two solanaceaus plants, Solanum viarum and Lycopersicon esculentum. Curr. Sci. $90,846-850$.

Subchev, M., Toshova, T., Tóth, M., Voigt, E., Mikulás, J. and Francke, W. (2004): Catches of vine bud moth Theresimima ampellophaga (Lep., Zygaenidae: Procridinae) males in pheromone traps: effect of the purity and age of baits, design, colour and height of the traps, and daily sexual activity of males. Z. Angew. Ent. 128, 44-50.

Tóth, M., Imrei, Z. and Szöcs, G. (2000): Non-sticky, non-saturable, high capacity new pheromone traps for Diabrotica virgifera virgifera (Coleoptera: Chrysomelidae) and Helicoverpa (Heliothis) armigera (Lepidoptera: Noctuidae). Integr. Term. Kert. Szántóf. Kult. 21, 44-49. (in Hung.)

Tóth, M., Landolt, P., Szarukán, I., Nagy, A. and Jósvai, J. K. (2019): Improving bisexual lures for the silver Y moth Autographa gamma L. and related Plusiinae (Lepidoptera: Noctuidae). Acta Phytopath. et Entomol. Hung. 54, 137-146.

Tóth, M., Szarukán, I., Dorogi, B., Gulyás, A., Nagy, P., and Rozgonyi, Z. (2010): Male and female noctuid moths attracted to synthetic lures in Europe. J. Chem. Ecol. 36, 592-598.

Wall, C. (1989): Evaluation and use of behaviour-modifying chemicals. In: A. R. Jutsum, and R. F. S. Gordon (eds): Insect Pheromones in Plant Protection. Wiley, Chicester, pp. 39-60.

Witzgall, P., Kirsch, P. and Cork, A. (2010): Sex pheromones and their impact on pest management. J. Chem. Ecol. 36, 80-100.

Open Access statement. This is an open-access article distributed under the terms of the Creative Commons Attribution 4.0 International License (https://creativecommons.org/licenses/by/4.0/), which permits unrestricted use, distribution, and reproduction in any medium, provided the original author and source are credited, a link to the CC License is provided, and changes - if any - are indicated. (SID_1) 